\title{
Efeito de derivados de nim aplicados por pulverização sobre a mosca- branca em meloeiro
}

\author{
Ervino Bleicher; Manoel E de C Gonçalves; Leonardo D da Silva \\ UFC - CCA, Av. Mister Hull, 2977, Campus do Pici. C. Postal 6012, 60356-001 Fortaleza-CE; E-mail: ervino@ufc.br; \\ eneascarvalho@ibest.com.br; dantasleo@yahoo.com.br
}

\section{RESUMO}

A mosca-branca é uma das principais pragas do meloeiro na região Nordeste do Brasil. Estudou-se neste trabalho o efeito de extratos aquosos de folhas e de sementes de nim (Azadirachta indica A. Juss.) e uma formulação à base de azadiractina comparados com o inseticida buprofezin, aplicados por pulverização, sobre ninfas da mosca-branca, Bemisia tabaci biotipo B, em melão cv. Torreon, sob condições de casa de vegetação. Três experimentos independentes foram realizados no delineamento inteiramente casualizado, com sete tratamentos e número variável de cinco a sete repetições. Cada planta constituiu uma unidade experimental. No primeiro experimento, os tratamentos foram: testemunha absoluta (água), Neemazal ${ }^{\circledR}(1,2 \%$ de azadiractina) nas doses 12; 24; 48; 96 e 192 ppm de azadiractina. No segundo: testemunha absoluta (água), extrato de semente a 1; 2; $4 ; 8$ e $16 \mathrm{~g} / 100 \mathrm{ml}$. No terceiro, o extrato de folhas foi aplicado nas mesmas proporções que o de sementes. Para cada experimento aplicou-se como testemunha positiva, o produto comercial Applaud ${ }^{\circledast}$ (buprofezin) na dose de 1,5g. p.c./L, que corresponde a $0,375 \mathrm{~g}$ de ingrediente ativo(i.a)/L de calda. A azadiractina foi eficiente em todas as doses causando redução de até $98 \%$ na média de ninfas vivas. Quando aplicado acima de 24 ppm, este composto apresentou desempenho semelhante ao inseticida padrão buprofezin. Os extratos de sementes a 1;2; 4; 8 e 16g/100 $\mathrm{ml}$ reduziram significativamente a média de ninfas vivas, não diferindo da ação do inseticida padrão. Os extratos de folha não foram eficientes no controle de ninfas.

Palavras-chave: Bemisia tabaci biótipo B, Azadirachta indica, Cucumis melo, controle alternativo, inseticida.

\begin{abstract}
Effects of neem derivatives sprayed on melon crop to control silverleaf whitefly

Whitefly is one of the main pests of melon in the Northeast area of Brazil. In this research, the effect of leaf and seed aqueous extracts of the neem plant (Azadirachta indica A. Juss.) and a formulation containing azadirachtin compared to buprofezin were studied as a spray application against nymphs of the silverleaf, Bemisia tabaci biotype $\mathrm{B}$, whitefly in greenhouse conditions on melon cv. Torreon. Three independent essays were performed using a completely randomized design, with seven treatments each and replication varying from five to seven. Each plant was considered as an experimental unit. On the first essay the treatments were: absolute control (water), Neemazal ${ }^{\circledR}(1.2 \%$ Azadirachtin) at doses of $12 ; 24$; 48; 96 and $192 \mathrm{ppm}$ of azadirachtin. On the second: absolute control (water) and seed extract using 1;2; 4; 8 and $16 \mathrm{~g} / 100 \mathrm{ml}$. On the third, leaf extract was applied at the same rate as for seeds. For each essay a positive control was added by using the commercial product Applaud® (Buprofezin) at 1.5 g.c.p./L, which corresponds to $0.375 \mathrm{~g}$ of the active ingredient (i.a.)/L of water. Azadirachtin at all dosages was effective and caused up to $98 \%$ reduction on alive nymphs number. When applied over $24 \mathrm{ppm}$, this compound showed the same efficiency as the standard buprofezin. The seed extracts, when used at $1 ; 2 ; 4 ; 8$ and $16 \mathrm{~g} / 100 \mathrm{ml}$, significantly reduced the alive nymphs number showing the same performance as the standard insecticide. The leaf extracts did not show a significant effect on nymphs.
\end{abstract}

Keywords: Bemisia tabaci biotipo B, Azadirachta indica, Cucumis melo, alternative control, insecticide

\section{(Recebido para publicação em 07 de maio de 2006; aceito em 10 de abril de 2007)}

$\mathrm{O}$ melão é uma das espécies olerícolas de maior expressão econômica e social para a região Nordeste do Brasil, com grande potencial produtivo, geradora de divisas e, por possuir boa aceitação comercial, rapidamente conquistou o mercado, tanto nacional como internacional (Pedrosa, 1995).

As condições climáticas da região Nordeste são propícias para o cultivo do melão. No entanto, são também favoráveis ao desenvolvimento de pragas. A mosca-branca, Bemisia tabaci (Genn.) biótipo B (= Bemisia argentifolii Bellows \& Perring), inseto polífago e de rápida reprodução, surge como uma das mais severas. Seu controle normal- mente é feito com produtos químicos convencionais que, embora eficientes, devido ao seu uso frequiente e de forma inadequada, têm causado desequilíbrio biológico e o surgimento de insetos resistentes (Prabhaker et al., 1985; Bleicher \& Melo, 1999).

Tendo em vista o potencial de dano e os prejuízos que a mosca-branca pode causar às lavouras de melão, outras alternativas de controle, como os inseticidas naturais têm sido pesquisadas. Uma das alternativas que surge atualmente é o uso de derivados do nim indiano (Azadirachta indica A. Juss.). Esta meliácea é amplamente estudada como repelente, inibidora de alimentação e reguladora de crescimento para várias espécies de pragas, e também por possuir relativa seletividade para inimigos naturais (Schmutterer, 1990, 1997; Sabillon \& Bustamante, 1995). Vários compostos secundários já foram isolados da planta, sendo a azadiractina considerada a mais importante, por ter eficácia comprovada no controle de diversas pragas agrícolas (Mordue \& Blackwell, 1993).

$\mathrm{O}$ nim tem sido relatado por pesquisadores como uma ferramenta promissora para o manejo integrado de pragas por atuar de várias formas sobre os insetos. O presente trabalho teve por objetivo avaliar extratos de folhas e de 
sementes de nim e uma formulação à base de azadiractina, aplicados por pulverização, visando ao controle de ninfas da moscabranca B. tabaci biotipo B, em meloeiro.

\section{MATERIAL E MÉTODOS}

A criação dos insetos para utilização nos experimentos foi conduzida em casa de vegetação. A partir de infestação natural, as colônias foram estabelecidas em plantas de melão cultivadas em vasos contendo uma mistura de $10 \%$ de substrato de casca de arroz + bagana (resíduo da folha de carnaúba após a retirada da cera), $10 \%$ de vermiculita, $30 \%$ de húmus de minhoca e $50 \%$ de areia.

As sementes foram coletadas de plantas com cerca de seis anos de idade, na Embrapa Semi-Árido, em Petrolina-PE, em setembro de 2002, e as folhas de plantas com quatro anos na Estação Experimental da Embrapa Agroindústria Tropical, em ParaipabaCE, em fevereiro de 2003. O produto formulado $\mathrm{Neemazal}^{\circledR}$, contendo 1,2\% de azadiractina, foi obtido na empresa Agripec Química e Farmacêutica, localizada no município de Maracanaú-CE.

A secagem das sementes foi realizada à temperatura ambiente. As folhas foram secas em estrados de madeira à temperatura ambiente e à sombra. Estes materiais foram posteriormente acondicionados a $4^{\circ} \mathrm{C}$. As sementes foram moídas em liquidificador até a obtenção do pó, enquanto para as folhas utilizou-se um moinho elétrico de facas. Os extratos foram preparados adicionandose quantidades, em gramas, de cada material ( $1 ; 2 ; 4 ; 8$ e 16 g do pó) em 100 $\mathrm{ml}$ de água destilada no interior de recipientes de vidro. A mistura permaneceu em repouso por 24 horas para extração das substâncias bioativas responsáveis pela ação inseticida. Em seguida, foi filtrado com tecido de algodão fino.

Os experimentos foram conduzidos sob condições de casa de vegetação, à temperatura máxima de $34,7 \pm 2,5^{\circ} \mathrm{C}$, mínima de $25,5 \pm 1,4^{\circ} \mathrm{C}$ e umidade relativa de $70 \pm 10 \%$. Estas variáveis foram obtidas em termômetros de temperatura máxima e mínima e de bulbo seco e úmido. O melão híbrido Torreon foi plantado em copos plásticos de $300 \mathrm{ml}$ de capacidade, com o mesmo substrato utilizado na manutenção da colônia de insetos.

Tabela 1. Eficiência de azadiractina e buprofezin, aplicados por pulverização, sobre ninfas da mosca-branca, Bemisia tabaci biotipo B, em plantas de melão (Efficiency of azadiractina and buprofezin, pulverized on nymphs of the whitefly Bemisia tabaci biotyp B, on melon plants). Fortaleza, UFC, 2002.

\begin{tabular}{lccc}
\hline Tratamento & Dosagem & $\begin{array}{c}\text { Ninfas vivas } \\
\left(\mathbf{n}^{\circ} \text { médio) }\right.\end{array}$ & Eficiência (\%) \\
\hline Testemunha & - & $13,33 \pm 9,9 \mathrm{a}^{1}$ & - \\
Azadiractina & $12 \mathrm{ppm}$ & $2,46 \pm 1,1 \mathrm{~b}$ & 82,3 \\
Azadiractina & $24 \mathrm{ppm}$ & $0,89 \pm 0,97 \mathrm{bc}$ & 93,3 \\
Azadiractina & $48 p p m$ & $0,68 \pm 0,75 \mathrm{bc}$ & 94,9 \\
Azadiractina & $96 \mathrm{ppm}$ & $0,13 \pm 0,24 \mathrm{c}$ & 99,1 \\
Azadiractina & $192 \mathrm{ppm}$ & $0,16 \pm 0,28 \mathrm{c}$ & 98,8 \\
Buprofezin & $0,375 \mathrm{~g} \mathrm{i.a/L}$ & $0,03 \pm 0,09 \mathrm{c}$ & 99,8 \\
\hline CV $(\%)$ & \multicolumn{3}{c}{}
\end{tabular}

${ }^{1}$ Tukey, 5\%. Para análise estatística, os dados foram transformados em $\sqrt{X+0,5}$ (Tukey's test, $\mathrm{p}<0,05$. For analysis, raw data were transformed to $\sqrt{X+0,5}$ ).

Três experimentos independentes foram realizados no delineamento inteiramente casualizado, com sete tratamentos e número variável de cinco a sete repetições. Cada planta constituiu uma unidade experimental. No primeiro experimento, os tratamentos foram: testemunha absoluta (água), Neemazal ${ }^{\circledR}(1,2 \%$ de azadiractina) nas doses 12; 24; 48; 96 e 192 ppm de azadiractina. No segundo: testemunha absoluta (água), extrato de semente a 1 ; $2 ; 4 ; 8$ e 16 g/100ml. No terceiro, o extrato de folhas foi aplicado nas mesmas proporções que o de sementes. Para cada experimento aplicou-se como testemunha positiva, o produto comercial Applaud $^{\circledR}$ (buprofezin) na dose de 1,5 g. p.c./L, que corresponde a $0,375 \mathrm{~g}$ de ingrediente ativo(i.a)/L de calda.

As plantas foram infestadas em gaiolas de confinamento de dimensões $1,0 \mathrm{x}$ $1,0 \times 0,5 \mathrm{~m}$, após 14 dias do plantio, na proporção de 40 adultos de mosca-branca não sexados e de idade desconhecida por planta. Após 48 horas, fez-se a retirada dos adultos e, em seguida, as plantas foram levadas para telado à prova de insetos. Decorridos sete dias, quando os insetos já se encontravam no primeiro estádio ninfal, os tratamentos foram aplicados com auxílio de um micropulverizador de êmbolo individualizado para cada tratamento. A pulverização foi direcionada para ambas as superfícies foliares até o ponto próximo ao escorrimento. A avaliação foi realizada sete dias após a aplicação dos tratamentos, contando-se as ninfas vivas em quatro discos de folha com $2,8 \mathrm{~cm}^{2}$ de área por planta, retirados da quarta folha a partir do ápice. As ninfas vivas eram facilmente visualizadas por estarem em estádio diferenciado de desenvolvimento, terem olhos bem visíveis e ocorrer extravasamento do conteúdo interno do corpo após serem perfuradas com alfinete. Em contraste, as ninfas mortas mantiveram tamanho característico de primeiro ínstar, corpo ressecado facilmente destacável da folha e olhos não visíveis. Calculou-se a média de ninfas vivas dos quatro discos foliares para representar o valor de uma repetição. Estes valores foram submetidos à análise de variância e quando constatado efeito significativo dos tratamentos, as médias foram comparadas pelo teste de Tukey ao nível de $5 \%$ de probabilidade. A eficiência dos tratamentos sobre as ninfas foi calculada segundo a fórmula de Abbott (1925).

\section{RESULTADOS E DISCUSSÃO}

A azadiractina causou redução na média de ninfas vivas já na menor dose, com nível acima de $80 \%$ de eficiência (Tabela 1). As quatro maiores doses de azadiractina igualmente afetaram a população de ninfas, com desempenho semelhante ao produto buprofezin, que é utilizado convencionalmente para o controle do inseto no campo. Estes resultados foram semelhantes aos encontrados por Gonçalves et al. (2002), que testaram, nas mesmas condições, a formulação Neemazal a 25 ppm de azadiractina sobre ninfas da mosca-branca, em plantas de melão híbrido Hymark. A aplicação de azadiractina a 50 ppm sobre 
Tabela 2. Eficiência de extratos aquosos de sementes de nim, Azadirachta indica, e buprofezin, aplicados por pulverização, sobre ninfas da mosca-branca, Bemisia tabaci biotipo $\mathrm{B}$, em plantas de melão (Efficiency of aqueous extracts of neem seeds (dirachta indica) and buprofezin, pulverized on whitefly nymphs). Fortaleza, UFC, 2002.

\begin{tabular}{lccc}
\hline Tratamento & Dosagem & $\begin{array}{c}\text { Ninfas vivas } \\
\left(\mathbf{n}^{\circ} \text { médio }\right)\end{array}$ & Eficiência (\%) \\
\hline Testemunha & - & $17,32 \pm 10,2 \mathrm{a}^{1}$ & - \\
Extrato de semente & $1 \mathrm{~g} / 100 \mathrm{ml}$ & $5,01 \pm 3,5 \mathrm{~b}$ & 71,1 \\
Extrato de semente & $2 \mathrm{~g} / 100 \mathrm{ml}$ & $3,69 \pm 4,6 \mathrm{~b}$ & 78,7 \\
Extrato de semente & $4 \mathrm{~g} / 100 \mathrm{ml}$ & $1,99 \pm 1,2 \mathrm{~b}$ & 88,5 \\
Extrato de semente & $8 \mathrm{~g} / 100 \mathrm{ml}$ & $0,67 \pm 0,7 \mathrm{~b}$ & 96,1 \\
Extrato de semente & $16 \mathrm{~g} / 100 \mathrm{ml}$ & $0,53 \pm 0,2 \mathrm{~b}$ & 97,0 \\
Buprofezin & $0,375 \mathrm{~g}$ i.a/L & $0,43 \pm 0,3 \mathrm{~b}$ & 97,5 \\
\hline CV $(\%)$ & \multicolumn{4}{c}{46,42} \\
\hline
\end{tabular}

${ }^{1}$ Tukey, 5\%. Para análise estatística, os dados foram transformados em $\sqrt{X+0,5}$ (Tukey's test, $\mathrm{p}<0,05$. For analysis, raw data were transformed to $\sqrt{X+0,5}$ ).

ninfas de primeiro ínstar de mosca-branca em meloeiro sob condições de casa de vegetação, resultou em uma eficiência acima de $96 \%$ (Lovato \& Vendramim, 2004), confirmando os resultados desta pesquisa. Por outro lado, Silva et al. (2003), nas mesmas condições, obtiveram resultados inferiores quando utilizaram azadiractina a 40; 80; 160 e 320 ppm aplicada em pré-infestação no meloeiro, atingindo no máximo $84 \%$ de eficiência na maior dose; no campo, ou seja, em pós-infestação, esses autores obtiveram eficiência acima de $80 \%$ nas duas primeiras doses. $\mathrm{O}$ fato de a pulverização, no presente trabalho, ter sido realizada diretamente sobre as ninfas de primeiro ínstar, sugere que, além da ingestão, a ação de contato tenha potencializado o efeito da azadiractina. A ação de contato deste composto sobre insetos tem sido demonstrada em outros estudos (Patel \& Srivastava, 1989; Stark \& Rangus, 1994).

No segundo experimento, todos os tratamentos contendo extratos de sementes reduziram significativamente a média de ninfas quando comparados à testemunha (Tabela 2). Registrou-se eficiência máxima de $97,0 \%$ quando foi usada a dose $16 \mathrm{~g} / 100 \mathrm{ml}$ em relação à testemunha. O desempenho dos extratos não diferiu do produto químico registrado para o controle da mosca-branca (buprofezin). Estes resultados concordam com os registrados por Gonçalves et al. (2002) ao testarem o extrato de nim a 2,5 g/100 $\mathrm{ml}$ sobre a mesma praga e hospedeiro. Da mesma forma, na concentração de $3 \mathrm{~g} / 100 \mathrm{ml}$, Souza \& Vendramim (2000) obtiveram 89\% de controle de B. tabaci biotipo B em tomateiro. Em estudos de laboratório, Coudriet et al. (1985), embora em menores doses, encontraram resultados equivalentes aos conseguidos nesta pesquisa, alcançando $100 \%$ de controle de ninfas de primeiro ínstar de B. tabaci. No campo, entretanto, a eficiência registrada por Dreyer (1990) foi inferior à desta pesquisa, quando o extrato de sementes de nim a $50 \mathrm{~g} / \mathrm{L}$, aplicado sobre plantas de berinjela para controlar a mosca-branca B. tabaci, resultou em $40 \%$ de controle de ninfas. Como as plantas de nim são cultivadas a partir de sementes, é possível que sejam originadas plantas com diferentes quantidades de azadiractina. De acordo com Martinez (2002), ocorreu variação de 2,90 a 6,10 mg de azadiractina por grama de semente, em amostras coletadas em países das Américas, África e Ásia, sendo encontrada neste último continente a maior concentração, tendo em vista ser o local de origem da planta. Além do local de origem, a parte coletada e idade da planta, forma de acondicionamento do material, método de extração e condições climáticas são fatores que influenciam na quantidade de compostos presentes na semente (Schmutterer, 1990; Martinez et al., 1998). Os resultados podem variar também em função da espécie de praga-alvo e tipo de hospedeiros (Lowery et al., 1993; Lowery \& Isman, 1994; Martinez, 2002).

Estudos sobre o controle de moscabranca utilizando óleo de sementes de nim têm mostrado eficiência equivalente à encontrada nesta pesquisa (Natarajan \& Sundaramurthy, 1990; Neves \& Pacheco, 2000).
Um complexo de compostos secundários já foi extraído de sementes de nim (Saxena, 1989). Assim, não se sabe ao certo a contribuição de tais compostos ao afetar a sobrevivência dos insetos. Sabe-se, no entanto, que a semente é o maior reservatório, principalmente de azadiractina, que é o mais conhecido tetranortriterpenóide isolado nesta parte da planta e considerado o mais importante (Butterworth \& Morgan, 1971; Jacobson, 1989; Rojatkar et al., 1989).

No terceiro experimento, os extratos de folha não foram eficientes para o controle de ninfas da mosca-branca quando comparados à testemunha (Tabela 3). A eficiência dos extratos não diferiu entre si. Na dose de $16 \mathrm{~g} / 100 \mathrm{ml}$, verificou-se que a média de ninfas vivas não diferiu da registrada no inseticida buprofezin embora tenha atingido apenas $56,3 \%$ de eficiência. $\mathrm{O}$ desempenho do extrato de folha a $2 \mathrm{~g} / 100 \mathrm{ml}$ coincide com os estudos de Gonçalves et al. (2002), que também não obtiveram desempenho satisfatório a 2,5 g/100 ml sobre ninfas da mosca-branca em plantas de melão.

A concentração de compostos secundários com possível ação inseticida nas folhas do nim é baixa quando comparada à da semente (Soon \& Bottrell, 1994). Segundo Balandrin et al. (1988), de um total de 25 compostos secundários identificados na planta, $75 \%$ estavam localizados nas sementes, enquanto os demais estavam presentes nas demais partes da planta. Isto justifica a baixa eficiência dos extratos aquosos de folhas nas concentrações aqui estudadas. De acordo com Hernandez (1995), na concentração de $5 \%(5 \mathrm{~g} / 100 \mathrm{ml})$, nenhuma estrutura vegetal de 14 meliáceas avaliadas provocou atividade inseticida superior à das sementes do nim. Outras meliáceas foram estudadas por Souza \& Vendramim (2001) para o controle de ninfas de B. tabaci biotipo B em tomateiro. Estes autores obtiveram baixa mortalidade, de 32 e $35 \%$, com os extratos de folhas de Trichilia pallida e Melia azedarach na proporção de $3 \mathrm{~g} /$ $100 \mathrm{ml}$, respectivamente; além de relatarem a variação na quantidade de compostos secundários em função da estrutura vegetal.

Os extratos de sementes exerceram forte atividade tópica sobre $B$. tabaci biotipo B em tomateiro (Souza, 2004). Por outro lado, azadiractina é por excelência 
um regulador de crescimento e atua principalmente por ingestão (Mordue \& Blackwell, 1993). A mortalidade máxima de B. tabaci, segundo Coudriet et al. (1985), ocorre entre 2 e 5 dias após o tratamento ou durante a ecdise. Estas afirmações sugerem que azadiractina e os extratos de sementes de nim atuaram tanto por contato como por ingestão, o que determinou sua eficiência mesmo nas menores dosagens estudadas.

A azadiractina e os extratos de sementes de nim, ao contrário do extrato de folhas, podem ser usados para o controle da mosca-branca em casa de vegetação, no entanto, devem ser estudados a campo para comprovar seu potencial no manejo integrado desta praga em meloeiro.

\section{AGRADECIMENTOS}

À Fundação Cearense de Apoio ao Desenvolvimento Científico e Tecnológico, pela concessão da bolsa de estudos ao segundo autor deste trabalho, e à Agripec Química e Farmacêutica pelo fornecimento do inseticida à base de azadiractina estudado nesta pesquisa.

\section{REFERÊNCIAS}

ABBOTT WS. 1925. A method of computing the effectiveness of an insecticide. Journal of Economic Entomology 18: 265-267.

BALANDRIN MF; MARK-LEE S; KLOCK JA. 1988. Biologically active volatile organosulphur compounds from seeds of the neem tree, Azadirachta indica (Meliaceae). Journal of Agriculture and Food Chemistry 36: 1048-1054.

BLEICHER E; MELO QMS. 1999. Controle químico da mosca-branca. Fortaleza: Embrapa Agroindústria Tropical. 2p. (Embrapa Agroindústria Tropical. Pesquisa em Andamento, 63).

BUTTERWORTH JH; MORGAN ED. 1971. Investigation of the locust feeding inhibition of the seeds of the neem tree, Azadirachta indica. Journal of Insect Physiology 17: 969-977.

COUDRIET DL; PRABHAKER N; MEYERDIRK DE. 1985. Sweetpotato whitefly (Homoptera: Aleyrodidae): Effects of neemseed extract on oviposition and immature stages. Environmental Entomology 14: 776-779.

DREYER M. 1990. Neem - a promising natural insecticide for small scale vegetable producers in the Dominican Republic. Dominican Republic: GTZ. 11p.

GONÇALVES MEC; SILVA LD; BLEICHER E. 2002. Extratos de nim e azadiractin no controle da mosca-branca em meloeiro. In: CONGRESSO BRASILEIRO DE OLERICULTURA, 42. Resumos... Uberlância: SOB (CD-ROM).

Tabela 3. Eficiência de extratos aquosos de folhas de nim, Azadirachta indica, e buprofezin, aplicados por pulverização, sobre ninfas da mosca-branca, Bemisia tabaci biotipo B, em plantas de melão (Efficiency of aqueous extracts of neem leaves (Azadirachta indica) pulverized on whitefly nymphs). Fortaleza, UFC, 2002.

\begin{tabular}{lccc}
\hline Tratamento & Dosagem & $\begin{array}{c}\text { Ninfas vivas } \text { ( }^{\circ} \\
\text { médio) }\end{array}$ & Eficiência (\%) \\
\hline Testemunha & - & $14,59 \pm 12,7 \mathrm{a}^{1}$ & - \\
Extrato de folha & $1 \mathrm{~g} / 100 \mathrm{ml}$ & $14,38 \pm 7,3 \mathrm{a}$ & 1,4 \\
Extrato de folha & $2 \mathrm{~g} / 100 \mathrm{ml}$ & $12,00 \pm 8,8 \mathrm{a}$ & 17,8 \\
Extrato de folha & $4 \mathrm{~g} / 100 \mathrm{ml}$ & $9,13 \pm 9,9 \mathrm{a}$ & 37,4 \\
Extrato de folha & $8 \mathrm{~g} / 100 \mathrm{ml}$ & $8,15 \pm 6,9 \mathrm{a}$ & 44,1 \\
Extrato de folha & $16 \mathrm{~g} / 100 \mathrm{ml}$ & $6,38 \pm 6,1 \mathrm{ab}$ & 56,3 \\
Buprofezin & $0,375 \mathrm{~g} \mathrm{i.a/L}$ & $0,13 \pm 0,2 \mathrm{~b}$ & 99,1 \\
\hline CV $(\%)$ & \multicolumn{4}{|c}{40,51} \\
\hline
\end{tabular}

${ }^{1}$ Tukey, 5\%. Para análise estatística, os dados foram transformados em $\sqrt{X+0,5}:$ (Tukey's test, $\mathrm{p}<0,05$. For analysis, raw data were transformed to $\sqrt{X+0,5}$ ).

HERNANDEZ CR. 1995. Efeitos de extratos aquosos de Meliaceae no desenvolvimento de Spodoptera frugiperda (J.E. Smith, 1797) (Lepidoptera: Noctuidae). Piracicaba: USPESALQ. 100p. (Tese doutorado).

JACOBSON M. 1989. Botanical Pesticides: past, present and future. In: ARNASON JT; PHILOGENE BJR; MORAND P. (Eds.) Insecticides of plant origin. Washington: The American Chemical Society. Symposium Series cap.1: 1-10.

LOVATO BV; VENDRAMIM JD. 2004. Eficiência de formulações comerciais a base de nim em relação a Bemisia tabaci (Genn.) biótipo B. In: CONGRESSO BRASILEIRODEENTOMOLOGIA, 20, Anais... Gramado: SEB. p. 588.

LOWERY DT; ISMAN MB; BRARD NL. 1993. Laboratory and field evaluation of neem for the control of aphids (Homoptera: Aphididae). Journal of Economic Entomology 86: 864-870.

LOWERY DT; ISMAN MB. 1994. Insect growth regulating effects of neem extract and azadirachtin on aphids. Entomologia Experimentalis et Applicata 72: 77-74.

MARTINEZ SS; LIMA J; BOIÇA JUNIOR AL. 1998. Avaliação agronômica e fotoquímica do neem, Azadirachta indica, de diferentes procedências em vários locais das regiões Sul e Sudeste do Brasil. In: CONGRESSO BRASILEIRO DE ENTOMOLOGIA, 17. Anais... Rio de Janeiro: SEB. p. 831.

MARTINEZ SS. 2002. O nim: Azadirachta. indica - natureza, usos múltiplos, produção. Londrina: $142 \mathrm{p}$.

MORDUE AJ; BLACKWELL A. 1993 Azadirachtin: an update. Journal of Insect Physiology 39: 903-924.

NATARAJAN K; SUNDARAMURTHY VT. 1990. Effect of neem oil on cotton whitefly (Bemisia tabaci). Indian Journal of Agricultural Sciences 60: 290-291.

NEVES BP; PACHECO MB. 2000. Eficiência do óleo de nim no controle da mosca-branca (Bemisa tabaci biótipo B) do feijoeiro. In: CONGRESSO BRASILEIRO DE DEFENSIVOS AGRÍCOLAS NATURAIS, 1. Anais... Fortaleza: ACC. p. 76.

PATEL MB; SRIVASTAVA KP. 1989. Evaluation of a neem oil formulation against cowpea aphid Aphis craccivora Koch. Neem Newsletter 6: 41-44.

PEDROSA J F. 1995. Cultura do Melão. Mossoró: ESAM. 39p.
PRABHAKER ND; COUDRIET DL; MEYERDIRK DE. 1985. Insecticide resistance in the sweetpotato Bemisia tabaci (Homoptera: Aleyrodidae). Journal of Economic Entomology 78:748-752.

ROJATKAR SR; BHAT VS; KULKARNI NM; JOSHI VS; NAGASAMPAGI BA. 1989. Tetranortriterpenoids from Azadirachta indica. Phytochemistry 28: 203-205.

SABILLON A; BUSTAMANTE M. 1995. Evaluación de extractos botánicos para el control de plagas del tomate (Lycopersicon esculentum Mill.). Ceiba 36: 179-187.

SAXENA RC. 1989. Insecticides from neem. In: ARNASON, JT; PHILOGENE BJR; MORAND P (Eds). Insecticides of plant origin. Washington: The American Chemical Society. Symposium Series cap. 10: 110-135.

SCHMUTTERER H. 1990. Properties and potential of natural pesticide from the neem tree, Azadirachta indica. Annual Review of Entomology 35: 271-297.

SCHMUTTERER H. 1997. Side-effects of neem (Azadirachta indica) products on insect pathogens and natural enemies of spider mites and insects. Journal of Applied Entomology 121: 121-128.

SILVA LD; BLEICHER E; ARAÚJO AC. 2003. Eficiência de azadiractin no controle da mosca-branca em meloeiro sob condições de casade-vegetação e campo. Horticultura Brasileira 21: 198-201.

SOON LG; BOTTRELL DG. 1994. Neem pesticides in rice: Potential and limitations. Manila: International Rice Research Institute. 69p.

SOUZA AP; VENDRAMIM JD. 2001. Atividade inseticida de extratos aquosos de meliáceas sobre Bemisia tabaci (Genn.) biótipo B. Neotropical Entomology 30: 133-137.

SOUZA AP; VENDRAMIM JD. 2000. Efeito de extratos aquosos de meliáceas sobre Bemisia tabaci biótipo B em tomateiro. Bragantia 59: 173-179.

SOUZA AP. 2004. Atividade inseticida e modos de ação de meliáceas sobre Bemisia tabaci (Genn. 1889) biotipo B. Piracicaba: USPESALQ 101p. (Tese doutorado).

STARK JD; RANGUS TM. 1994. Lethal and sublethal effects of the neem insecticide formulation, 'Margosan-O', on the pea aphid. Pesticide Science 41: 155-160. 